\title{
Assessment of Cardiovascular Risk in a Nigerian Rural Community as a Means of Primary Prevention Evaluation Strategy Using Framingham Risk Calculator.
}

\author{
Dr Ogunmola J. O. ${ }^{1}$, Dr Olaifa O.A. ${ }^{2}$, Dr Akintomide A.O. ${ }^{3}$ \\ ${ }^{I}$ Cardiac Centre, Department of Internal Medicine, Federal Medical Centre IdoEkiti, Ekiti State, Nigeria \\ ${ }^{2}$ Department of Internal Medicine, Federal Medical Centre IdoEkiti, Ekiti State, Nigeria \\ ${ }^{3}$ Department of Medicine, Cardiology Unit, ObafemiAwolowo University Teaching Hospitals Complex, Ile-Ife, \\ Osun state, Nigeria
}

\begin{abstract}
Objective: In view of the current trend of cardiovascular diseases in sub-Saharan Africa, coupled with the majority of the population in the rural setting and the need for preventive strategy, this study aimed at determining the 10-year absolute risk for cardiovascular events in rural setting of AayeEkiti, Ekiti State, South West Nigeria.

Methods: Cross sectional study was conducted in a typical rural community in Ekiti State, Southwest, Nigeria involving 183 participants aged 40 to 79 years. A well-structured questionnaire was administered to determine the sociodemographic variables and relevant risk factors such as age, gender, total cholesterol, high density lipoprotein cholesterol, smoking, and systolic blood pressure were determined. Framingham risk calculator was used to determine the 10-year absolute risk in line with National Cholesterol Education Program Adult Treatment Panel III Version.

Results:The study involved 183 participants, age range 60 to 79years, $34.4 \%$ were males while $65.6 \%$ were females. Over half $(59.1 \%)$ belong to the low risk $(<10 \%)$ category, while $31.1 \%$ belong to the intermediate risk category (10-20\%) and $9.8 \%$ belong to the high risk category $(>20 \%)$. There was statistical significant difference between males and females.

Conclusion:Based on the results, the high proportion of patients in the intermediate and high risk categories suggest need for necessary preventive intervention strategy to be part of health care program in the rural settings.
\end{abstract}

Key Words: Risk factors, risk assessment, Nigeria,rural community, Primaryprevention.

\section{Introduction}

Cardiovascular diseases now cause most deaths in all developing regions with its lead cause of deaths in those older than 45years occurring in sub-Saharan Africa ${ }^{1}$. In absolute number, cardiovascular disease (CVS) causes four to five times as many deaths in developing countries as in developed countries. ${ }^{2}$

The emerging increases of CVD in developing countries underscore the crucial need to redouble treatment and prevention efforts. ${ }^{3}$ The concepts of risk assessment and reduction are the cornerstones of preventive cardiology practice.Some studies in Nigeria reported high risk factors of CVD. However, information on risk factors prevalence alone is insufficient to provide adequate knowledge on the risk of future cardiovascular events. Guidelines recommend that cardiovascular disease risk assessment in the form of risk scoring \{as recommended by National Cholesterol Education Program Expert Panelon Detection, Evaluation, and Treatment of High Blood Cholesterol in Adults (Adult Treatment Panel III) ${ }^{4}$ is used to identify patients who are asymptomatic but at high risk of adverse outcome from CVD in the future. ${ }^{4}$ United Kingdom guidelines recommended that all people aged 40 or more should have a routine cardiovascular risk assessment. ${ }^{5}$ Risk scoring methods enable clinicians to combine patient risk factor information and predict the risk of a cardiovascular event within a specified time period. The extent of this risk in a typical rural setting in a developing country like Nigeria is rarely known. Therefore, this study sets out to determine the absolute risk for coronary heart disease (CVD) over the next 10 years using Framingham scoring system which has been widely used in United States and Europe.

\section{Materials and Methods}

1.1 Study design:

The design was a single-centre, descriptive, cross-sectional survey.

\subsection{Study Population:}


This study was conducted in AayeEkiti, a typical rural community in Ido/OsiLocalGovernmentAreaof Ekiti State, Southwest of Nigeria. This village is located about $30 \mathrm{~km}$ from Ado-Ekiti, the state capital. Agriculture is the major occupation of the people, mainly cultivation of root crops. It is a small rural community with an estimated population of 1610 people. The community is divided into four (4) quarters with a total number of 161 houses namely Onala (51 houses), Oke-Ode (28 houses), Odo-Ode (22 house), and Temidire (60 houses). These houses were visited for enrolment process. Eligible households were defined as ones having participants that meet up with inclusion criteria. One hundred and eighty three participantswere enrolled.

The study population was made up of adults aged 40years and above (excluding pregnant females) who have not been previously diagnosed with cardiovascular disease or diabetes mellitus, and have lived for at least three (3) years in the community. Participants in the community who met these inclusion criteria were mobilized through the community leader, chiefs, opinion leaders, including announcement in strategic places like church and community meetings. The comprehensive health centre available in the community was used to evaluate all participants recruited for the study.

The ethical committee of the Federal Medical Centre Ido-Ekiti, Ekiti State approved the study. Individual participant written consent was obtained. Confidentiality and data utilized for this study were stripped of personally identifiable information.

\subsection{Procedure:}

All professionals involved in this study were trained in the procedures to be adopted for data collection before commencement, to ensure uniformity and therefore minimize error.

A pre-test was undertaken and necessary modification adopted before main data collection was done.

Each participant was comfortably seated and assessed for all the variables including sociodemographic characteristics of the population. Socioeconomic status was assessed using a general model ${ }^{6,7}$ as a convenient index for classification into lower class, middle class, and upper class since majority of the population are peasant farmers.

The fasting blood glucose (FBG), Total Cholesterol (TC) and high density lipoprotein cholesterol (HDL-L) were determined using capillary blood obtained from pin prick on finger pulp using Cardio check P. A. polymer technology system, Inc., a point of care analyser which is a reliable alternative to conventional laboratory devices following the relevant manufacturers guidelines and instructions.

Accuracy of the equipment was $\pm 6 \%$ compared to the standard laboratory result. Sample volumes needed for the devices were drop of blood for cholesterol (TC and HDL-C) using a micropipette, and one drop of blood for glucose applied directly from the fingertip. Diabetes Mellitus and impaired fasting blood glucose was diagnosed according to the World Health Organization (WHO) diagnostic criteria. ${ }^{8}$

Smoking was considered present in individuals confirming smoking status as at time of interview.

Blood pressure (Bp) was measured with mercury sphygmomanometer at least twice in each participant after at least 5 minutes of rest in between, with the subject seated in a chair and relaxed, the back supported, and the arm bare, and at heart level. During the screening, both arms Bp were measured and the arms with high Bp record were used. Cuff sizes were adjusted to arm circumference for overweight/obese individuals. Tobacco, alcohol and caffeine were not allowed at least 30 minutes before taking the Bp. Bp was taken to the nearest $2 \mathrm{~mm}$ using phase 1 Korotkoff sound to determine the systolic Bp. Information on current medication, if any, to treat high Bp was noted. Overall cardiovascular risk was estimated using the Framingham Risk Score (FRS) for general cardiovascular disease (10-year risk). Events of this risk score are coronary death, myocardial infarction, coronary insufficiency, angina, ischaemic stroke, haemorrhagic stroke, transient ischaemic attack, peripheral artery disease and heart failure. Each participant was categorized using table 1 (Framingham risk assessment system for calculating 10-years risk), the number of points for each risk factor was estimated, and the global risk score (sum of points) were calculated, and the 10-year absolute risk level for CHD was assessed, with $<10 \%$ defined as low risk, $10-20 \%$ intermediate risk, and $>20 \%$ as high risk.

\subsection{Data Analysis:}

The mean and standard deviation of the quantitative variables were calculated. Student t-test was used for analysing the means and the Chi square test for the proportions. Computer software package (SPSS version 16.0) was used to generate the tables and the results of statistical analysis. For all analyses, $\mathrm{P}$ values less than 0.05 were considered statistically significant.

\section{Results}

This study involved 183 participants consisting of 63 (34.4\%) males and 120 (65.6\%) females, age ranged 40 to 79 years, mean $63.8 \pm 11.1$ years. The mean age for the male was $67.2 \pm 9.5$ years (age ranged 50 to 79 years), while the mean age for the female was $62.1 \pm 11.4$ years (age ranged 40 to 78 years). 
The participants mean systolic Bp was $148.1 \pm 27.6$ (male was $144.6 \pm 22.7$, while female was $149.9 \pm 27.7$ ). The mean for TC was $147.2 \pm 27.7$ (male was $142.2 \pm 26.7$, while female was $149.6 \pm 28.1$ ). The mean for the HDL-C was $51.6 \pm 19.7$ (male was $50.4 \pm 185$, while female was $52.3 \pm 20.5$ ).

In table 2, the total number of participants in each age group increases with age; and they predominantly belonged to low socioeconomic class $(88.5 \%)$ with over half $(51.4 \%)$ without any formal education, and $48.1 \%$ engaged in peasant farming while $27.9 \%$ engaged in petty trading.

Table 3 shows that majority of the participants $(59.1 \%)$ had low $(<10 \%)$ 10-year absolute risk for $\mathrm{CHD}$, and males were at a higher risk than females. The intermediate risk group was $31.1 \%$, while high risk group was $9.8 \%$.

\section{Discussion}

The majority of the participants in the community (59.1\%) were found to have low risk of developing myocardial infarction and coronary death in the next 10years from point of assessment. This finding may not be unconnected with the fact that CVD is known to be commoner in the wealthy population compared to the poor population. ${ }^{9}$ However, substantial percentage of the participants $(31.1 \%)$ fall within intermediate groups, suggesting those that will require life style modification and possibly appropriate test modalities that can further define risk state. The high risk probability of developing hard CHD (myocardial infarction and coronary death) over 10 years in this study population is high $(9.8 \%)$, meaning that 18 out of 183 people $(9.8 \%)$ have $20 \%$ chance of developing major cardiovascular events over the next 10years.

Therefore about 100,000 of 1million population of similar sociodemographic characteristics of this population studied will possibly be at high risk and moreso will require intensive life style modification and need to initiate pharmacologic intervention (intensive preventive interventions). This high proportion of 10-years risk may be explained by their low educational level and low socioeconomic class, since these had been shown to confer a greater risk of dying from heart disease in all ethnic groups. ${ }^{10}$

There is a statistical significant difference in 10-year risk score category between male and female. This is similar to previous evidence derived from the Framingham Heart study population showing higher risk in males compared to females ${ }^{11,12}$.

In this study, majority of the women (75\%) are in low risk category, which is comparable to previous study on global risk score using Framingham risk score. ${ }^{13,14}$

The proportion of participants in each age group increases with age in this study because, the young and the middle aged adults have migrated to the cities for greener pasture. So also, the female preponderance could be associated with possible early deaths in men as previously recognized ${ }^{15,16,17}$ and clearly in this study, men predominantly engaged in peasant farming (77.8\%) which is a more risky job compared to mostly petty trading in which their women were involved.

\section{Conclusion}

This study revealed a high proportion of patients in the intermediate and high risk categories of 10year absolute risk for CHD. We must suggest therefore, that there is need for necessary preventive intervention strategy to be part of health care programme in the rural setting of developing countries, and the need for clinicians to consider risk assessment as part of patients evaluation.The Framingham Risk Score could overestimate (or underestimate) risk in populations other than the US population, and within the USA in populations other than European Americans and African Americans, for example Hispanic Americans and Native Americans. It is not yet clear if this limitation is real, or appears to be real because of differences in methodology, and some other factors. However, FRS has been widely found to be useful.

If possible, a cardiology professional should select the risk prediction model which is most appropriate for an individual patient and should remember that this is only an estimate.Limitations of the FRS and NCEP/ATP III guidelines include a substantial underestimation of lifetime risk, especially in women when only a 10-year risk model is used. This should be considered in this study since most of the participants were women. So also, the population in this study was small of which future study could improve on. It is recommended that future studies in our environment should consider various scores as to determine the best.

\section{References}

[1]. Thomas AG, Michael JG: Global Burden of cardiovascular Disease: Braunwald's Heart Disease; A textbook of Cardiovascular Medicine (9th Edition, Elsevier's Health Sciences Right Department in Philadelphia, PA, USA) p1 - 20.

[2]. Murray CJL, LOPEZ AD: The global burden disease. A comprehensive assessment of mortality and disability from disease, injuries, and risk factors in 1990 and projected to 2020 (Cambridge, MA: Harvard University Press, 1996).

[3]. Hennekens $\mathrm{CH}$ : Increasing burden of cardiovascular disease: Current knowledge and future directions for research on risk factors. Circulation 1998; 97: 1095-1102 
[4]. Expert Panel on Detection, Evaluation, and Treatment of High Blood Cholesterol in Adults. Executive Summary of the third report of the National Cholesterol Education Program (NCEP) Expert Panel on Detection, Evaluation, and Treatment of High Blood Cholesterol in Adults Adult treatment Panel III), JAMA 2001; 285: 2486 - 2497.

[5]. De Backer G, Ambrosioni E, Borch-JohnsonK, Brotons C, Cifkova R, Dallongerille J; et al . European guidelines on cardiovascular disease prevention in clinical practice Eur Heart J. 2003; 24: 1601 -1610.

[6]. Reza GS, Hadi A, Babak D: Socieconomic status and class perception. Iranian journal of Language Studies (IJLS) 2007; 3:183 200.

[7]. Brown DF: "Social class and status" (Mey, Jacob. CoinciseEncyclopedia of pragmatics. Elsvier. 2009) P.953.

[8]. World Health Organization, International Diabetes Federation: Definition and diagnosis of diabetes mellitus and intermediate hyperglycaemia report of a WHO/IDF consultation 2006, page 1-6. Available at http://www.who.int/diabetes/publications/diagnosis. Accessed $25^{\text {th }}$ September, 2012.

[9]. Mathers CD, Lopez A, stein C: Deaths and Disease burden by cause: Global burden of disease estimates for 2001 by World Bank Country Groups, 2005. Disease Control Priorities working Paper. Available at http://www.dcp2.org. Accessed $25^{\text {th }}$ September 2012.

[10]. Mensah GA; Mokdad AH; Ford ES; etal: State of disparities in cardiovascular health in the United States, Circulation 2005; 111: 1233-1241.

[11]. Lloyd-Jones DM; Larson MG; Beiser A; Levy D: lifetime risk developing coronary heart disease, Lancet 1999;353:89-92.

[12]. Lloyd Jones DM; LeipEP;Larson MG; etal : Prediction of lifetime risk for cardiovascular disease by risk factor burden at 50years of age. Circulation 2006;113: 791-798.

[13]. Pasternak RC; Abrams J, Greenland P; et al: $34^{\text {th }}$ Bethesda Conference: task force $\# 1$ - identification of coronary heart disease risk: is there a detection gap? JAMCollcardiol 2003; 41: 1863-1874.

[14]. Nasir K; Michos ED; Blumenthal RS; Raggi P: Detection of high risk young adults and women by Coronary Calcium and National Cholesterol Education Program Panel III guidelines, J Am CollCardiol2005;46:1931 - 1936.

[15]. Jneid H, Fonarow GC, Cannon CP: Sex differences in medical care and early death after acute myocardial infarction Circulation 2008;118:2803

[16]. Lyoyd-Jones D, Adams R, Carnethon: Heart disease and stroke statistics-2009 update: A report from the American Heart Association Statistics Committee and stroke statistics Subcommittee. Circulation 2009; 119:21.

[17]. Yusuf S, Reddy S, Onnpuu S, Anand S: Global burden of cardiovascular diseases: Part I: General considerations, the epidemiol ogic transition, risk factors, and impact of urbanization. Circulation 2001; 104:2746

Table 1: Framingham Risk Assessment System for Calculating 10-year Risk

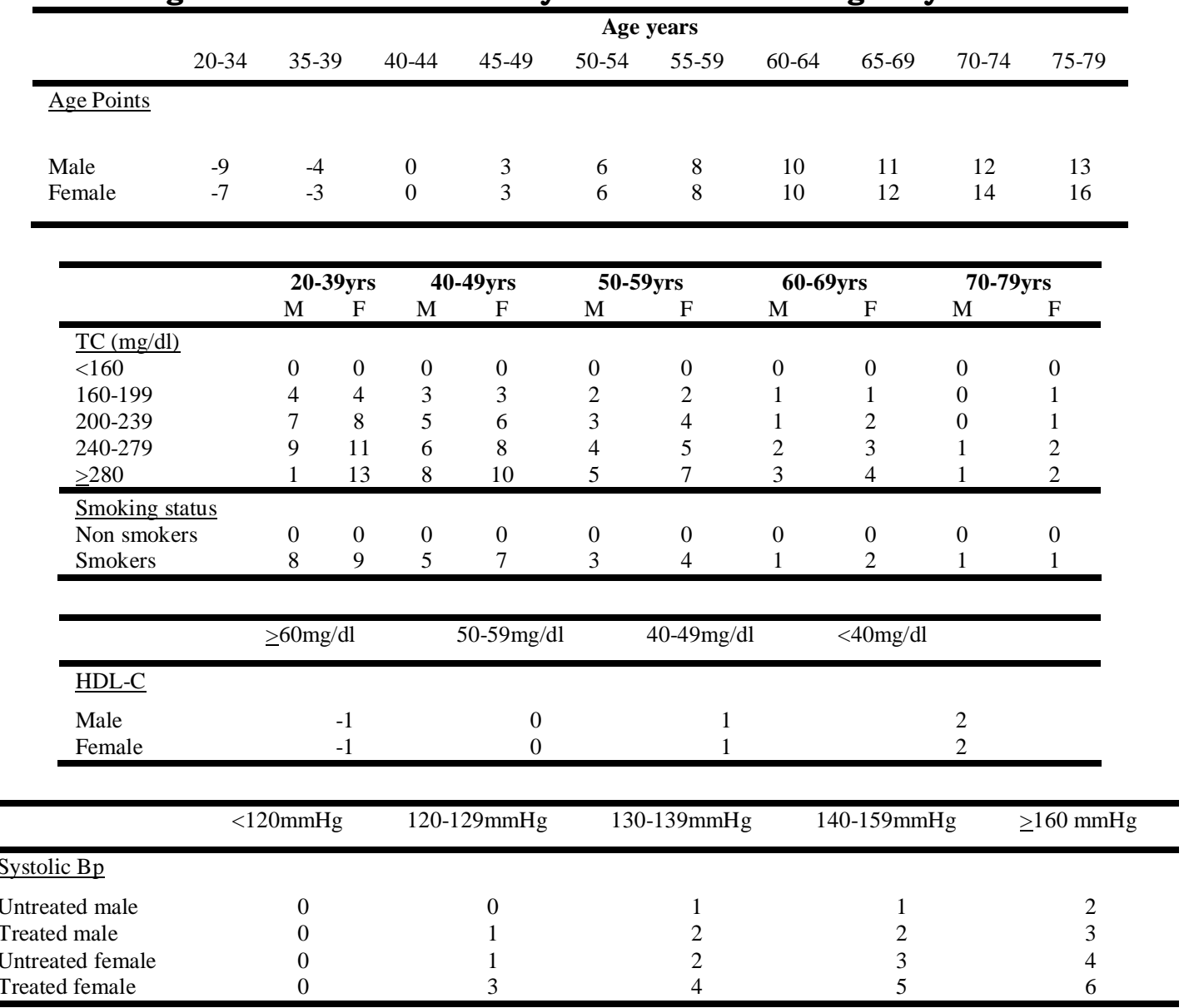


Final point Assessment Scale

Males

\begin{tabular}{|c|c|c|c|c|c|c|c|c|c|c|c|c|c|c|c|c|c|c|c|}
\hline Point total & $<0$ & 0 & 1 & 2 & 3 & 4 & 5 & 6 & 7 & 8 & 9 & 10 & 11 & 12 & 13 & 14 & 15 & 16 & $\geq 17$ \\
\hline 10 -year risk \% & $<0$ & 1 & 1 & 1 & 1 & 1 & 2 & 2 & 3 & 4 & 5 & 6 & 8 & 10 & 12 & 16 & 20 & 25 & $\geq 13$ \\
\hline \multicolumn{20}{|l|}{ Females } \\
\hline Point total & $<9$ & 9 & 10 & 11 & 12 & 13 & 14 & 15 & 16 & 17 & 18 & 19 & 20 & 21 & 22 & 23 & 24 & & \\
\hline 10 -year risk \% & $<1$ & 1 & 1 & 1 & 1 & 2 & 2 & 3 & 4 & 5 & 6 & 8 & 11 & 14 & 17 & 22 & 27 & & \\
\hline
\end{tabular}

TC, Total cholesterol; HDL-C, High density lipoprotein cholesterol.

Table 2: Sociodemographic characteristics of the participants by Sex.

\begin{tabular}{rllllr}
\hline VariablesMale $(\mathrm{N}=63)$ & Female $(\mathrm{N}=120)$ & Total $(\mathrm{N}=183)$ & $\mathrm{X}^{2}$ & dfP-Value \\
$\mathrm{N}$ & $(\%)$ & $\mathrm{N}$ & $(\%)$ & $\mathrm{N}$ & $(\%)$
\end{tabular}

\section{Age group (years)}

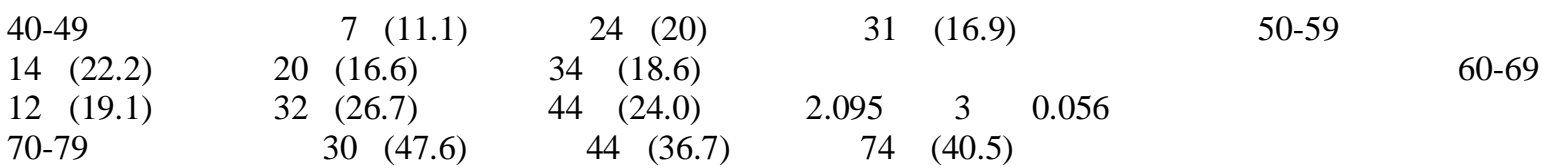

\section{Socioeconomic Status}

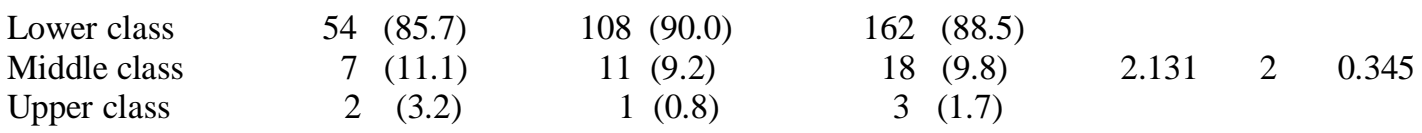

\section{Highest educational level attained}

\begin{tabular}{|c|c|c|c|c|c|c|c|}
\hline No formal education & $26(41.3)$ & $68 \quad(56.6)$ & 94 & $(51.4)$ & & & \\
\hline Primary school & $13(20.6)$ & $30 \quad(25.0)$ & 43 & $(23.5)$ & & & \\
\hline Secondary school & $9(14.3)$ & $11(9.2)$ & 20 & $(10.9)$ & 4.466 & 3 & 0.215 \\
\hline Post-secondary school & $15(23.8)$ & $11(9.2)$ & 26 & (14.2) & & & \\
\hline
\end{tabular}

\section{Occupation}

\begin{tabular}{|c|c|c|c|c|c|c|c|c|}
\hline Farming & 49 & (77.8) & $39 \quad(32.5)$ & 88 & $(48.1)$ & & & \\
\hline Trading & 4 & (6.3) & $47(39.2)$ & 51 & (27.9) & 20.902 & 2 & 0.000 \\
\hline Others & 10 & (15.9) & 34 (28.3) & 44 & $(24.0)$ & & & \\
\hline
\end{tabular}

Table 3: Category of 10-year absolute risk percent by Sex.

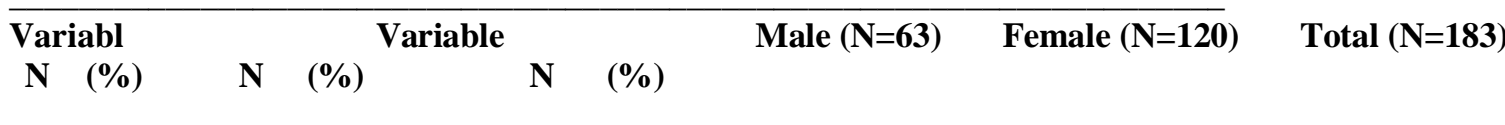

10-year Absolute risk percent

$\begin{array}{lrlrlrl}\text { Low risk }(<10 \%) 18 & (28.6) & & 90 \quad(75) & & 108 & (16.9) \\ \text { Intermediate risk }(10-20 \%) & 35 & (55.6) & 22 & (18.3) & 57 & (31.1) \\ \text { High risk }(>20 \%) & 10 & (15.8) & 8 & (6.7) & 18 & (9.8)\end{array}$

$X^{2}=26.041 \mathrm{df}=2 P-$ Value $=0.000$ 